\title{
Peertechz
}

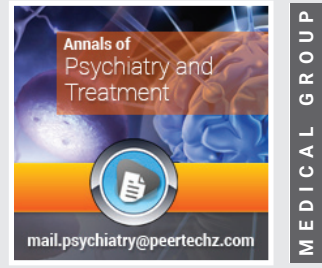

\section{First manic episode in}

\section{4-year-old adolescent during COVID-19 pandemic lockdown}

\section{measures: A case report}

Received: 17 June, 2020

Accepted: 30 June, 2020

Published: 02 July, 2020

*Corresponding author: Simone Marchini, Department of Child and Adolescent Psychiatry, Erasme Hospital, Université Libre de Bruxelles (ULB), Brussels, Belgium, Email: Simone.Marchini@ulb.be

ORCID: https://orcid.org/0000-0002-0432-5705 https://www.peertechz.com

Check for updates

\section{Simone Marchini*, Ode Van Ormelingen and Marie Delhaye \\ Department of Child and Adolescent Psychiatry, Erasme Hospital, Université Libre de Bruxelles (ULB), \\ Brussels, Belgium}

\begin{abstract}
The authors describe a 14-year-old adolescent presenting a first manic episode begun during COVID-19 lockdown measures. The patient was experiencing extreme psychological discomfort about the lockdown measures. Family environment was described as stressful and freedom limitation perceived as extremely oppressive. The inpatient care and pharmacological intervention allowed rapid symptoms remission. The present early onset manic episode follows the model combining the personal vulnerability with a strong triggering factor. The authors conclude that the role of COVID-19 pandemic and its implication on adolescent's mental health needs to be further investigated.
\end{abstract}

\section{Introduction}

Lifetime prevalence of all adolescent Bipolar Disorders (BD) varies from $0.1 \%$ to $1 \%[1,2]$. The incidence rates of first-onset mania in clinical sample of youth range from 1.7 to 2.2 per 100 000 per year [3].

Both genetic [4] and life events [5] play a role in the onset of BD. The early onset of this disorder seems to be explained by the interaction model between bio-psychological vulnerability and environmental stressors.

The recent investigation of which psychosocial factors potentially trigger the onset of manic episode in youth highlighted precise events in adolescents life such as falling in love, recreational stimulant use, starting a creative project, late night partying, going on vacation and listening to loud music [6].

COVID-19 pandemic outbreak can be consider as an important stressor factor for mental health in specific vulnerable groups, such as adolescents [7]. Anxious and depressive symptoms increase and sleep perturbation in adolescence have already been assessed [8]. Potentially dangerous intra-familial dynamics need to be monitored. During previous public health emergencies, it has been reported that social isolation and economic instability could predispose increased rates of intra-familial abuse [9].

The authors present in this paper the case of a 14-year-old adolescent presenting a first manic episode during COVID-19 pandemic lockdown measures. The role of this global context of continuous health concerns and freedom limitation in triggering the onset of the present first manic episode is discussed.

\section{Case report}

In April 2020, a 14-year-old North African boy with acute onset of a manic episode was admitted to the Adolescent Psychiatry Unit of the Erasme Hospital in Brussels.

The patient was referred from another hospital's Paediatric Unit in Brussels. The main symptom leading the boy and his family to this hospital consisted of lack of sleep starting 2 weeks previously. The boy was observed with grandiose and logorrheic speech, psychomotor agitation, exalted mood. Parents reported the appearance of sexually oriented thoughts 
with illogical correlations, for example, he was convinced that the cause of insomnia consisted in the impossibility to masturbate himself. All these symptoms gradually appeared a week after the lockdown measures in Belgium.

Once admitted in the Adolescent Psychiatry Unit, the following symptoms were observed by the psychiatrist: incoherent speech, grandiosity (he thought he was God and he could save the world), sleep fragmentation, tachypsychia, hyperactivity and euphoric mood. One episode of auditory hallucination was described: he heard shouts and little stones hitting the window, he felt terrified about this.

The 14-year-old adolescent was being spending the lockdown measures at home with his own family, composed by his father, his mother and an elder brother aged of 18 years old. The flat where they were living in was perceived by the patient as oppressive and lacking of private space. The risk of incomes decreases due to COVID-19 restrictive measure particularly concerned the boy's father. This potential financial instability caused a very anxious atmosphere inside the whole family. None in the family contracted the COVID-19; the patient was tested negative while he was at the hospital.

Concerning his personal history, undefined learning difficulties were reported. The patient has been held back two grades at school. He followed a 5 years long speech and language therapy and a 2 years psychomotricity. Nor relevant somatic disease neither toxics abuse was reported.

No psychiatric familial history has been reported. A mixed lingual context was described: both parents were speaking Arab, but the mother spoke in Dutch to her children, whereas the father in French.

Both blood tests and brain image were not suggestive of a somatic cause explaining the symptoms.

During the first days of hospitalisation, an antipsychotic medication was necessary. The parents of the patient initially refused. The medical and nursing team cooperate to work on therapeutic alliance and Aripiprazole $10 \mathrm{mg}$ could be rapidly started. For the first days, association with Zuclopenthixol 15 $\mathrm{mg} /$ day revealed to be necessary.

Clinical evolution was impressive; few days after the beginning of the medical treatment, the adolescent showed to be calmer and he could participate to the activities with the other patients. After every activity, one-hour rest was planned for him. The patient and the family followed a specific psychoeducational program. The 14-years-old was discharged after two weeks of inpatient care. A great collaboration with parents was established.

Psychiatric follow-up during following weeks after the end of the hospitalisation was reassuring. The patient showed a stabilized mood and continued the prescribed drug (Aripiprazole $10 \mathrm{mg} /$ day). Sleep and speech were described as normal. He achieved to participate to distance education program following the Belgian COVID-19 managing rules.

\section{Discussion}

The principal risk factor for $\mathrm{BD}$ is familial-genetic factor [10]. Apparently, the 14-years-old boy was not concerned. Nevertheless, the patient learning difficulties history seems to suggest a neuro-biological background of vulnerability. Children with BD are reported to have greater rates of arithmetic and reading learning disabilities as compared to healthy volunteers [11]. It rests difficult to determine whether theses cognitive difficulties represent a risk factor or a negative consequence of early onset manic episodes. In the presented case, the acute phase chronologically occurred after the emergence of learning issues.

COVID-19 pandemic can be considered one of the most widely spread psychological stressor in our society. The authors suggest that this period played a crucial role in triggering the presented early onset manic episode. Low socio-economic status and social isolation are already known to be potentially risk factor to develop BD in adolescence [12]. The patient felt stressed by the familial environment and oppressed. Because of lockdown measures, he could not freely move outside his house. On the other hand, incomes instability due to COVID-19 work reorganisation seemed to concern the adolescent's parents. Financial loss is one of the main stressor highlighted in the actual literature about COVID-19 [13].

Inpatient care improved the patient's symptoms in an extremely rapid way. Many factors can help to understand this fact. Certainly, the quick and efficient psychopharmacological treatment is one of the best prognostic factor for early-onset BD [12]. Secondly, symptoms rapid onset led to psychiatric evaluation in less than one week from the beginning. Parents could obviously notice any change in their son's behaviour during lockdown measures. Under these particular conditions, early treatment has been possible.

In addition, the separation from the parents allowed to ease intra-familial tensions linked to COVID-19. A neutral and securing living place was offered to the adolescent to recover work on his insight. The parents could better explore their behaviour towards their son's symptoms and enhance a great therapeutic alliance.

\section{Conclusion}

COVID-19 pandemic represented one of the biggest stress factors on mental health of the contemporary world. All the implications of this period, such as lockdown measures and widely spread fear of contagion, determined the increase of children and adolescents needs in Psychiatry care. At-risk population have been psychologically affected more than others have. The described case report follows the interaction between bio-psychological vulnerability and environmental triggers to develop psychopathology. Further researches on this interactive model should be pursued in the light of the COVID-19 pandemic. The rapid symptoms remission needs particular attention: raising awareness programs on early stage symptoms seem to appear crucial in adolescent psychiatry in order to assure rapid intervention and treatment. 


\section{References}

1. Kim-Cohen J, Caspi A, Moffitt TE, Harrington H, Milne BJ, et al. (2003) Prior Juvenile Diagnoses in Adults With Mental Disorder. Arch Gen Psychiatry 60: 709. Link: https://bit.ly/38hJfJj

2. Lewinsohn PM, Klein DN, Seeley JR (1995) Bipolar Disorders in a Community Sample of Older Adolescents: Prevalence, Phenomenology, Comorbidity, and Course. J Am Acad Child Adolesc Psychiatry 34: 454-463. Link: https://bit.ly/31zcLc8

3. Soutullo CA, Chang KD, Diez-Suarez A, Figueroa-Quintana A, Escamilla-Canales I, et al. (2005) Bipolar disorder in children and adolescents: international perspective on epidemiology and phenomenology. Bipolar Disord 7: 497-506. Link: https://bit.ly/2YSLwrD

4. Craddock N, Jones I (1999) Genetics of bipolar disorder. J Med Genet 36: 585594. Link: https://bit.ly/2BUT2sK

5. Johnson SL, Cueller AK, Ruggero C, Winett-Perlman C, Goodnick P, et al. (2008) Life events as predictors of mania and depression in bipolar I disorder. J Abnorm Psychol 117: 268-277. Link: https://bit.ly/38fTbmG

6. Proudfoot J, Whitton A, Parker G, Doran J, Manicavasagar V, et al. (2012) Triggers of mania and depression in young adults with bipolar disorder. $\mathrm{J}$ Affect Disord 143: 196-202. Link: https://bit.ly/2BZNvkz

7. Labana RV (2020) The public mental health while in a community quarantine due to COVID-19 pandemic: A scoping review of literature using Google Scholar. Link: https://bit.ly/2YNyjzX

8. Zhou SJ, Zhang LG, Wang LL, Guo ZC, Wang JQ, et al. (2020) Prevalence and socio-demographic correlates of psychological health problems in Chinese adolescents during the outbreak of COVID-19. Eur Child Adolesc Psychiatry Link: https://bit.ly/31zlpaE

9. Lee J (2020) Mental health effects of school closures during COVID-19. Lancet Child Adolesc Heal 4: 421. Link: https://bit.ly/31EMrOB

10. DelBello MP, Geller B (2001) Review of studies of child and adolescent offspring of bipolar parents. Bipolar Disord 3: 325-334. Link: https://bit.ly/31FrVwu

11. Wozniak J, Biederman J, Kiely K, Ablon JS, Faraone SV, et al. (1995) ManiaLike Symptoms Suggestive of Childhood-Onset Bipolar Disorder in Clinically Referred Children. J Am Acad Child Adolesc Psychiatry 34: 867-876. Link: https://bit.ly/2VxLgw4

12. Carlson GA, Findling RL, Post RM, Birmaher B, Blumberg HP, et al. (2009) AACAP 2006 Research Forum-Advancing Research in Early-Onset Bipolar Disorder: Barriers and Suggestions. J Child Adolesc Psychopharmacol 19: 3-12. Link: https://bit.ly/31v15ax

13. Brooks SK, Webster RK, Smith LE, Woodland L, Wessely S, et al. (2020) The psychological impact of quarantine and how to reduce it: rapid review of the evidence. Lancet 395: 912-920. Link: https://bit.ly/2Zrp6wr
Discover a bigger Impact and Visibility of your article publication with

Peertechz Publications
Highlights

* Signatory publisher of ORCID

* Signatory Publisher of DORA (San Francisco Declaration on Research Assessment)

* Articles archived in worlds' renowned service providers such as Portico, CNKI, AGRIS, TDNet, Base (Bielefeld University Library), CrossRef, Scilit, J-Gate etc.

* Journals indexed in ICMJE, SHERPA/ROMEO, Google Scholar etc.

- OAI-PMH (Open Archives Initiative Protocol for Metadata Harvesting)

* Dedicated Editorial Board for every journal

- Accurate and rapid peer-review process

* Increased citations of published articles through promotions

* Reduced timeline for article publication

Submit your articles and experience a new surge in publication services (https://www.peertechz.com/submission).

Peertechz journals wishes everlasting success in your every endeavours.

Copyright: @ 2020 Marchini S, et al. This is an open-access article distributed under the terms of the Creative Commons Attribution License, which permits unrestricted use, distribution, and reproduction in any medium, provided the original author and source are credited. 